\title{
Medical education: Historical perspective
}

Dixit $\mathbf{H}$

Principal and Consultant Paediatrician, Kathmandu Medical College

$\mathrm{W}$ ith the evolution of the human race and its existence on earth, it is but natural that early man should have been plagued with disease. Our Vedic scriptures tell us that Brahma wrote the slokas in the Vedas. The Rig and Ather Vedas documented knowledge about medical and surgical diseases and their treatment. Subsequent followers such as Sage Agastya practised the healing arts then. The oral tradition then passed on this medical knowledge to the practitioners such as Susruta and Charak. Even Jesus Christ, with his curing of the lepers may be called a practitioner of the healing arts. The Romans with their herbal and knife doctors played a major role in the spread of medical practise in all areas of their conquest. The proponents of these healing arts are a galaxy of names such as Hippocrates, Galen, Rhazes, Avicenna, Vesalius, Pare, Jenner, Harvey and Sydenham. The knowledge of healing, initially passed on by learned men of the times, was taken up by priest practitioners too and was handed down from generation to generation by a system based on a period of apprenticeship in the various societies and guilds existing in those days. The system of apprenticeship produced great surgeons such as Hunter and Astley Cooper. Societies like that of the Apothecaries licensed the practitioners in the practise and art of healing sciences.

The system prevalent in Europe was in course of time transported to Asia, Africa and the Americas. The scientific teachers of the English, French, Spanish and Portuguese medical schools took along their scientific know-how and technologies to their respective colonies and domains and put these into practice there.

We in Nepal have been mainly influenced by the medical practices introduced by the British to the Indian subcontinent. Their system had to prevail over the prevalent systems in use e.g. Ayurved, Siddha and Unani. This system of Western medicine, initially restricted to the urban areas, spread all over the Indian Continent. We in Nepal have been influenced by it.

As the practise of medicine spread, there came a demand for the increase of the practitioners. Many took this up, not only to do good and serve humanity but for monetary benefit and pecuniary interests. With the influx of learners, schools or institutions for the training of these came into existence. The initial cumbersome process of rote learning and passing on knowledge had speeded up, first with the process of writing and later with the introduction by Caxton of the printing press in the $15^{\text {th }}$ Century. With the advent of the electronic based information technology there has now been even more extensive and explosive growth of knowledge and its dissemination. The days of rote learning and keeping of extensively large libraries are limited by the availability of wide ranging knowledge at one's fingertips, provided of course that one knows how and where to look for it. With the increasing awareness of environmental degradation and the limited production of paper from tree sources we are on the threshold of limited use of paper. The computer is here to stay with us and the days of a paperless world may not be far off.

The new mantra for learning may be said to be "Seek and ye shall find, look and ye shall see and remember." Problem Based Learning which had been introduced as far back as the late seventies at McMaster has spread to different corners of the globe and is being utilised for teaching / learning not only in medicine but also in various other faculties and department. We in Nepal have been toying with its use for some years. More extensive utilisation appears certain in the future. 